\title{
Temperature-dependent development rates of Bracon vulgaris, a parasitoid of boll weevil
}

\author{
F. S. Ramalho • P. A. Wanderley • J. B. Malaquias • \\ K. C. V. Rodrigues • J. V. S. Souza • J. C. Zanuncio
}

Received: 8 February 2008 / Accepted: 12 August 2008 / Published online: 25 November 2008

(C) Springer Science + Business Media B.V. 2008

\begin{abstract}
The duration of development of Bracon vulgaris Ashmead, parasitoid of the boll weevil Anthonomus grandis Boheman, was determined at nine constant temperatures between $18^{\circ} \mathrm{C}$ and $38^{\circ} \mathrm{C}$. Nonlinear regression analysis was used to test the fit of temperature-dependent development rates to the Sharpe and DeMichele and Lactin et al. models. At the highest tested temperature $\left(38^{\circ} \mathrm{C}\right)$ all the parasitoid eggs died before hatching and no evidence of development was observed. The high values of $R^{2}$ for the models of Sharpe and DeMichele (0.8432 to 0.9834), and Lactin et al. (0.9071 to 0.9795$)$ indicated that these models are suitable to estimate the development rate of $B$. vulgaris as a function of temperature. $B$. vulgaris showed tolerance to high temperature which is represented by the high value of $H_{\mathrm{H}}$ (change in enthalpy associated with high-temperature inactiva-
\end{abstract}

F. S. Ramalho $(\bowtie) \cdot J$. B. Malaquias $\cdot$ K. C. V. Rodrigues • J. V. S. Souza

Unidade de Controle Biológico (UCB)/Embrapa Algodão, 58107-720 Campina Grande, State of Paraíba, Brazil

e-mail: framalho@pesquisador.cnpq.br

\section{P. A. Wanderley}

Centro de Formação de Tecnólogos da UFPB,

Bananeiras, PB., Brazil

\section{J. C. Zanuncio}

Departamento de Biologia Animal, Universidade Federal de Viçosa,

36571-000 Viçosa, State of Minas Gerais, Brazil tion of the enzyme) for the prepupa stage of this insect obtained with the Sharpe and DeMichele model. According to that model, B. vulgaris exhibits thermal stress at $35.7^{\circ} \mathrm{C}$, which indicates that maximum thermal stress estimated by this model was close to the real one.

Keywords Anthonomus grandis · Nonlinear models . Sharpe and DeMichele model $\cdot$ Lactin et al. model

\section{Introduction}

The ectoparasitoid Bracon vulgaris Ashmead is a major natural enemy which may be employed for reduction of boll weevil (Anthonomus grandis Boheman) populations in the cotton agro-ecosystems in the Brazilian northeast (Ramalho et al. 1993).

The relationship between development rate and temperature represents an important ecological tool to model population dynamics of insects (Howe 1967; Uvarov 1931; Wanderley et al. 2007). Several authors (e.g. Lactin et al. 1995; Schoolfield et al. 1981) formulated mathematical models to describe this relationship. The knowledge of such relationships is important to determine seasonal occurrences of insect populations in integrated pest management strategies (Marco et al. 1997).

Modeling the effect of $B$. vulgaris on the boll weevil's population dynamics is an important step in 
implementing a biological control program against this pest, applying augmentation tactics. Determining development rates as a function of temperature is required for the development of a simulation model of parasitoid-host population dynamics under changing temperatures. Because temperatures normally exceed $35^{\circ} \mathrm{C}$ at least during part of summer days in Brazil, high-temperature inhibition of $B$. vulgaris became a concern. For this reason, temperature-dependent development rates were fit to two nonlinear models, namely, the Sharpe and DeMichele model (Sharpe and $\mathrm{Hu}$ 1980) and one variant (Lactin et al. 1995) of the model of Logan et al. (1976). Such models provide estimates of temperatures at which inhibition occurs. This study is the first step in the construction of a detailed population simulation model to predict field phenology and density of B. vulgaris to help optimize the use of this biological control agent in controlling boll weevil at various locations throughout northeastern Brazil.

\section{Materials and methods}

The research was carried out at the Biological Control Unit (BCU) of the National Center for Cotton Plant Research (Embrapa Cotton), Campina Grande, Paraíba State, Brazil. B. vulgaris specimens were obtained from third generation colonies of the BCU/Embrapa Cotton. Third instar A. grandis larvae were collected in upland cotton bolls (Gossypium hirsutum L. race latifolium Hutch.) CNPA Precoce cultivar planted at Embrapa Cotton Research and used as a rearing host. The research was carried out in environmental chambers at constant temperatures $\left(18^{\circ} \mathrm{C}, 20^{\circ} \mathrm{C}, 23^{\circ} \mathrm{C}, 25^{\circ} \mathrm{C}\right.$, $28^{\circ} \mathrm{C}, 30^{\circ} \mathrm{C}, 33^{\circ} \mathrm{C}, 35^{\circ} \mathrm{C}$, and $\left.38^{\circ} \mathrm{C}\right), 70 \pm 10 \%$ r.h. and 14L/10D photoperiod.

Cotton bolls attacked by $A$. grandis were collected and taken to the laboratory and dissected. Third instar larvae of this insect were removed and disinfected with $10 \%$ sodium hypochlorite for $10 \mathrm{~min}$, after which they were transferred to the previously molded parafilm pads. These parafilm pads with larvae were taken to the rearing box and exposed to gravid females of $B$. vulgaris for $6 \mathrm{~h}$. The parasitized larvae were placed individually on ELISA plastic plate wells, with one parasitoid egg fixed in the dorsal region of each boll weevil larva. Fifty B. vulgaris eggs were used for each constant temperature. The number of larval instars of $B$. vulgaris was determined by marking the cuticle of the parasitoid larvae with Day-Glow powder. The change of instar was confirmed by two criteria: the absence of the powder mark on the cuticle and the presence of the marked parasitoid exuviae. The immature forms of this parasitoid were observed every $6 \mathrm{~h}$ with a stereoscopic microscope. The duration of egg incubation, larval instars, prepupa and pupal stages of B. vulgaris was registered.

Mean development rate of B. vulgaris at different temperatures was estimated with the formula:

$D_{\mathrm{M}}=1.0 / \exp \left[\left(\sum_{i=1}^{n} \ln \left(d_{i}\right)\right) / n\right]$

where $D_{\mathrm{M}}$ is the daily mean rate of development at temperature $T\left({ }^{\circ} \mathrm{C}\right) ; d_{\mathrm{i}}$, individual observations of development time in days; and $n$ is the sample size. This method is recommended by Logan et al. (1976) to account for linearity in the transformation from development time to development rate.

Development rate is the reciprocal of development time in days and it is represented by values from 0 to 1. These rates are used in development models where data are added each day. The development of an organism is completed when the sum of their daily rate of development reaches 1 (Cury and Feldman 1987). Therefore, the integral of the function of development rate along time as the methods of Sharpe and DeMichele (1977) and Lactin et al. (1995) can be used to simulate the development of an organism submitted to changes in temperature. For this reason, descriptive nonlinear procedures have been used to analyze the relationship between development rate of B. vulgaris and temperature as described.

The Sharpe and DeMichele (1977) biophysical model, modified by Schoolfield et al. (1981), is represented by the following equation:

$R(T)=\frac{\mathrm{RHO}_{25}\left(\frac{T}{298.15}\right) \exp \left[\left(\frac{H_{A}}{\mathrm{Rq}}\right)\left(\frac{1}{298.15}-\frac{1}{T}\right)\right]}{1+\exp \left[\left(\frac{H_{\mathrm{L}}}{\mathrm{Rq}}\right)\left(\frac{1}{T_{\mathrm{L}}}-\frac{1}{T}\right)\right]+\exp \left[\left(\frac{H_{\mathrm{H}}}{\mathrm{Rq}}\right)\left(\frac{1}{T_{\mathrm{H}}}-\frac{1}{T}\right)\right]}$

where $R(T)$ is the mean development rate (equivalent to $\left.D_{\mathrm{M}}\right)$ at temperature $T(\mathrm{~K})$; the universal gas 
constant (1.987 cal K $\mathrm{mol}^{-1}$ ), $\mathrm{RHO}_{25}$; the development rate at $25^{\circ} \mathrm{C}\left(298.15^{\circ} \mathrm{K}\right)$, assuming no enzyme inactivation; $H_{\mathrm{A}}$, the enthalpy of activation of the reaction that is catalyzed by a rate-controlling enzyme; $T_{\mathrm{L}}$ Kelvin temperature at which the rate-controlling enzyme is half active and half low-temperature inactive; $H_{\mathrm{L}}$, the change in the enthalpy associated with low temperature inactivation of the enzyme; $T_{\mathrm{H}}$, Kelvin temperature at which the rate-controlling enzyme is half active and half high-temperature inactive; and $H_{\mathrm{H}}$, the change in the enthalpy associated with high-temperature inactivation of the enzyme. The parameters $\mathrm{RHO}_{25}, H_{\mathrm{A}}, T_{\mathrm{H}}$ and $H_{\mathrm{H}}$ were estimated by Marquardt's method using PROC NLIN (SAS Institute 2004) with the procedure adopted by Wagner et al. (1984).

The numerator of the second equation explains the dependent development rates of the temperature in the absence of inactivation at low or high temperatures, while first and second exponential equations in the denominator explain, respectively, the inhibition at low and high temperatures (Wagner et al. 1984). Wagner et al. (1984) developed a method to determine if data are adjusted by a model constituted by six, four or two parameters. This method tests the nonlinearity of data to extreme temperatures (low and high), which would indicate inhibition at extreme temperatures. The model is constituted by six parameters and it is better adjusted to the data if neither extreme temperature has a significant effect on the inhibition. When high temperatures have no effect on inhibition, the parameters $T_{\mathrm{H}}$ and $H_{\mathrm{H}}$ will assume constant values of $10^{3}$ and $10^{8}$, respectively. If low temperature does not have a significant effect on the inhibition, the parameters $T_{\mathrm{L}}$ and $H_{\mathrm{L}}$ will receive constant values of 100 and $-10^{8}$, respectively. Therefore, in both cases, a four-parameter model would fit the data better. When low and high temperatures have no effect on inhibition, the model with two parameters will better fit the data; then, the four parameters $T_{\mathrm{H}}$, $H_{\mathrm{H}}, T_{\mathrm{L}}$ and $H_{\mathrm{L}}$ will receive constant values of $10^{3}$, $10^{8}, 100$, and $-10^{8}$, respectively.

The values of the parameters $T_{\mathrm{H}}$ and $T_{\mathrm{L}}$ were estimated for boll weevil females using the published data of Bacheler et al. (1975). Similarly, data published by Barfield et al. (1977) on development rates of $B$. mellitor females were used to estimate $T_{\mathrm{H}}$ and $T_{\mathrm{L}}$.
The model of Lactin et al. (1995) resulted from the modification of the nonlinear model of Logan et al. (1976):

$R(T)=e^{\rho T}-e\left[\rho T_{L}-\left(\frac{T_{L}-T}{\Delta_{T}}\right)\right]+\lambda$

where $R(T)$ is the mean development rate at temperature $T\left({ }^{\circ} \mathrm{C}\right) ; T_{\mathrm{L}}$, lethal temperature $\left({ }^{\circ} \mathrm{C}\right) ; \rho$, rate of increase at optimal temperature; $\Delta_{\mathrm{T}}$, difference between lethal and optimal temperature of development; and $\lambda$, the parameter that makes the curve intercept the $x$-axis, allowing to estimate development threshold. The parameter $\lambda$ is the value of the rate $R$ ( $T_{\mathrm{L}}$ ) (i.e., when $T=T_{\mathrm{L}}$ ) and allows the curve to intersect the abscissa at suboptimal temperatures, permitting estimation of the base temperature by allowing $R(T)=0$ to be solved for particular parameter values. The upper threshold (Tupper) is the value of $T$ for which $R(T)$ is maximum (i.e., the first derivative, $R^{\prime}(T)$, is equated to zero and solved for $\left.T\right)$, then $R^{\prime}(T)=$ $\mathrm{d} R(T) / \mathrm{d} T=\rho \times \exp \left(\rho^{T}\right)-\left(1 / \Delta_{\mathrm{T}}\right) \times \exp \left[\rho \times T_{\mathrm{L}}-\left(T_{\mathrm{L}}-T\right) /\right.$ $\Delta_{\mathrm{T}}$ ] which evaluated at $T=0$ gives the initial rate, equivalent to parameter $b$ of the $x$-intercept method. The value of $T$ for which $R^{\prime}(T)=0$ is then Tupper= $\left[\Delta_{\mathrm{T}} \times \log _{\mathrm{e}}\left(\Delta_{\mathrm{T}} \times \rho\right) /\left(1-\Delta_{\mathrm{T}} \times \rho\right)\right]+T_{\mathrm{L}}$, which is equivalent to the expression given by Logan et al. (1976). Parameters $T_{\mathrm{L}}, \rho, \Delta_{\mathrm{T}}$, and $\lambda$ were estimated by Marquardt's method using PROC NLIN (SAS 2004).

The coefficient of determination $\left(R^{2}\right)$ of nonlinear models cannot be calculated as in linear models $\left[R^{2}=\right.$ $1-(\mathrm{SSR} / \mathrm{TSS})]$, mainly because most nonlinear models do not contain an identifiable intercept term. As a consequence, the SAS software uses the uncorrelated sum of squares as total sum of squares (Freund and Littell 1986). The $R^{2}$ of these models were calculated as $R^{2}=1\left(S_{\text {YERR }}^{2} / S_{\mathrm{D}}^{2}\right)$, where $S^{2}$ YERR is the variance of the model residuals and $S^{2}{ }_{\mathrm{D}}$ is the variance of the observed means of development rates. This method was used by Wagner et al. (1984) to obtain $R^{2}$ in their SAS program.

\section{Results and discussion}

Temperature and development The duration of the egg $[F(1,395)=2.42 ; P=0.178]$, larva $[F(1,371)=$ $1.02 ; P=0.210]$, prepupa $[F(1,258)=1.87 ; P=0.322]$ 


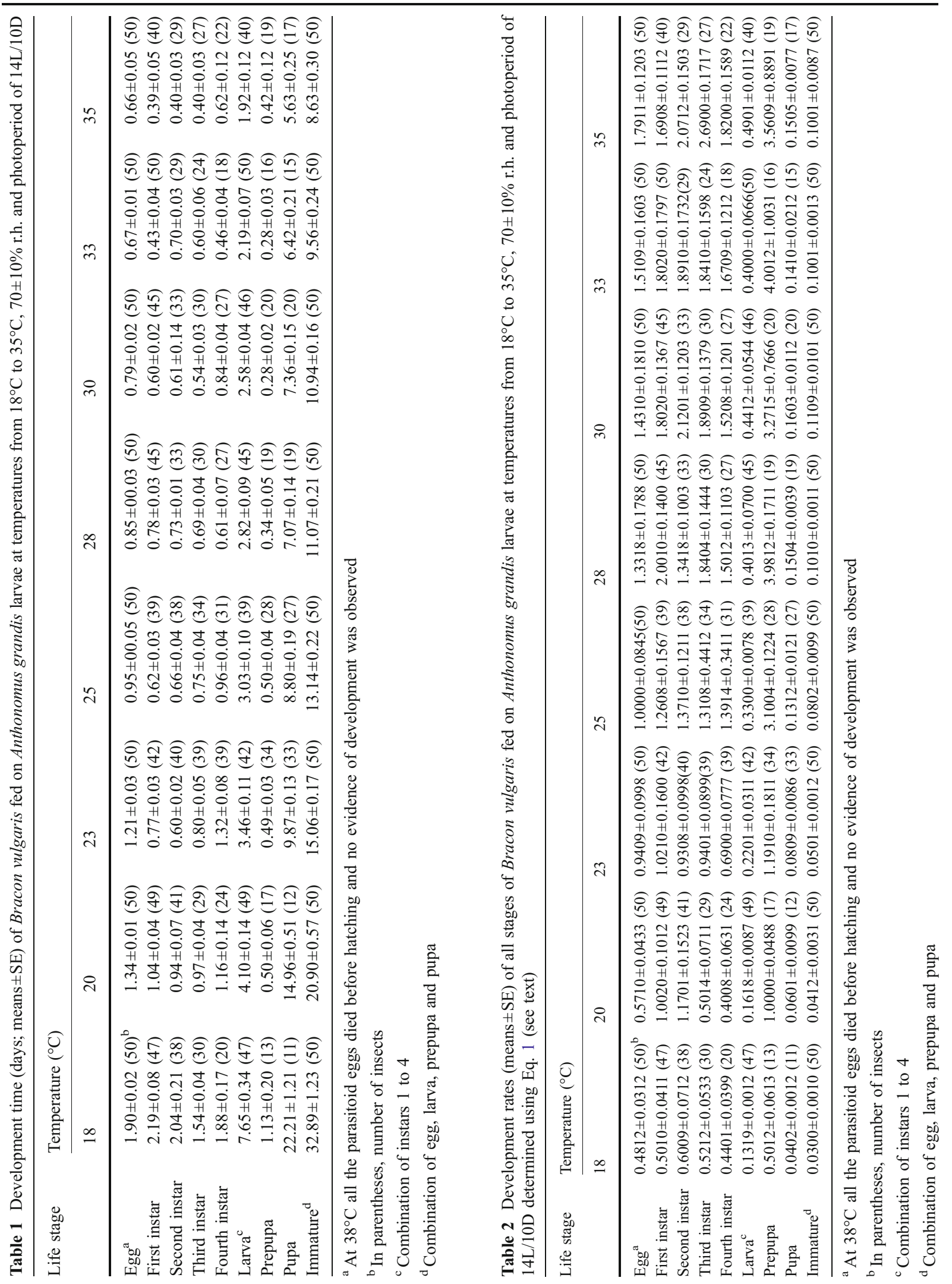


Table 3 Parameters estimated by Sharpe and DeMichele (1977) model (standard errors within parentheses) for development stages of Bracon vulgaris fed on Anthonomus randis larvae at temperatures from $18^{\circ} \mathrm{C}$ to $35^{\circ} \mathrm{C}, 70 \pm 10 \%$ r.h. and photoperiod of $14 \mathrm{~L} / 10 \mathrm{D}$

\begin{tabular}{|c|c|c|c|c|c|c|}
\hline \multirow[t]{2}{*}{ Stage } & \multicolumn{6}{|l|}{ Parameter } \\
\hline & $R H O_{25}^{\mathrm{a}}$ & $H_{\mathrm{A}}^{b}$ & $T_{\mathrm{H}}^{c}$ & $T_{\mathrm{H}}^{d}$ & $R^{2}$ & $P$ value \\
\hline Egg & $7.0195(0.4568)$ & $50,389.0000(438.5430)$ & $291.0000(31.8310)$ & $45,603.2000(200.3212)$ & 0.9834 & $>0.0001$ \\
\hline First instar & $1.6422(0.3212)$ & $24,007.7000(231.3000)$ & $304.4000(32.8990)$ & $51,075.2000(99.3200)$ & 0.9164 & $>0.0003$ \\
\hline Second instar & $104.3000(23.3200)$ & $-49,308.3000(32.3000)$ & $311.0000(31.5000)$ & $62,709.8000(132.5000)$ & 0.8432 & $>0.0009$ \\
\hline Third instar & 7.4307 (1.9867) & $60,629.8000(110.2100)$ & $292.9000(32.3000)$ & $52,468.4000(100.1200)$ & 0.9332 & $>0.0005$ \\
\hline Fourth instar & $3.5081(0.9812)$ & $56,904.4000(234.0990)$ & $296.0000(31.786)$ & $56,984.4000(341.4590)$ & 0.9413 & $>0.0003$ \\
\hline Larva & $0.5739(0.1212)$ & $-3,137.4000(101.0234)$ & $297.4000(45.3412)$ & $41,630.2000(210.5432)$ & 0.9547 & $>0.0001$ \\
\hline Prepupa & $6.2715(1.1678)$ & $71,147.5000(231.1234)$ & $297.6000(49.3454)$ & $77,080.8000(132.7689)$ & 0.9225 & $>0.0008$ \\
\hline Pupa & $0.2255(0.0112)$ & $41,444.8000199 .7688)$ & $298.7000(76.3421)$ & $52,035.6000(175.6510)$ & 0.9675 & $>0.0001$ \\
\hline Immature & $0.0955(0.0019)$ & $29,436.8000(120.5643)$ & $308.9000(89.1200)$ & $51,332.9000(123.6599)$ & 0.9749 & $>0.0001$ \\
\hline
\end{tabular}

${ }^{\text {a }}$ Development rate at $25^{\circ} \mathrm{C}\left(298.15^{\circ} \mathrm{K}\right)$ assuming no enzyme inactivation

${ }^{\mathrm{b}}$ Enthalpy of activation of the reaction that is catalyzed by a rate-controlling enzyme

${ }^{\mathrm{c}}$ Kelvin temperature at which the rate-controlling enzyme is half active and half high-temperature inactive

${ }^{\mathrm{d}}$ Change in the enthalpy associated with high-temperature inactivation of the enzyme

and pupa $[F(1,212)=2.05 ; P=0.101]$ stages and that of the first $[F(1,395)=1.95 ; P=-0.109)]$, second $F(1,371)=1.22 ; P=0.122]$, third $[F(1,264)=1.74$; $P=0.165]$ and fourth $[F(1,244)=1.99 ; P=0.199]$ instar larvae did not differ significantly between males and females of the parasitoid. Thus, the data for the two sexes were pooled and analyzed together.

The mean development times in days for all stages at all the experimental temperatures are presented in
Table 1. At the highest tested temperature $\left(38^{\circ} \mathrm{C}\right)$ all the parasitoid eggs died before hatching and no evidence of development was observed. The lethality of this temperature was not instantaneous, and the parasitoids probably died as a consequence of longterm exposure to high temperature stress. High mortality at extreme constant temperatures may result from different mortality agents and inactivation of enzymes (Sharpe and DeMichele 1977).

Table 4 Parameters estimated by Lactin et al. (1995) model (standard errors within parentheses) for development stages of Bracon vulgaris fed on Anthonomus grandis larvae at temperatures from $18^{\circ} \mathrm{C}$ to $35^{\circ} \mathrm{C}, 70 \pm 10 \%$ r.h. and photoperiod of $14 \mathrm{~L} / 10 \mathrm{D}$ and computation of base temperatures and upper thresholds $\left({ }^{\circ} \mathrm{C}\right)$

\begin{tabular}{|c|c|c|c|c|c|c|c|c|}
\hline \multirow[t]{2}{*}{ Stage } & \multicolumn{4}{|l|}{ Parameter } & \multirow[t]{2}{*}{$R^{2}$} & \multirow[t]{2}{*}{$P$ value } & \multirow[t]{2}{*}{ Base temperature } & \multirow[t]{2}{*}{ Upper threshold } \\
\hline & $\rho^{\mathrm{a}}$ & $T_{\mathrm{L}}^{b}$ & $\Delta_{\mathrm{T}}^{c}$ & $\lambda^{\mathrm{d}}$ & & & & \\
\hline Egg & $0.0517(0.0012)$ & $52.7056(0.5612)$ & $10.6923(0.0112)$ & $-1.4664(0.1787)$ & 0.9795 & $>0.0008$ & 8.12 & 38.53 \\
\hline First instar & $0.0551(0.0019)$ & $41.5447(0.4532)$ & $5.9402(1.5432)$ & $-1.9452(0.3123)$ & 0.9071 & $>0.0157$ & 9.01 & 31.68 \\
\hline Second instar & $0.0366(0.0010)$ & $38.5673(0.8976)$ & $1.4894(0.8976)$ & $-1.1938(0.1212)$ & 0.9142 & $>0.0043$ & 11.80 & 33.98 \\
\hline Third instar & $0.0404(0.0102)$ & $38.0713(0.7489)$ & $0.1740(0.7653)$ & $-1.5536(0.9812)$ & 0.9461 & $>0.0002$ & 11.02 & 37.20 \\
\hline Fourth instar & $0.0410(0.0039)$ & $39.1013(0.9978)$ & $2.2188(0.8786)$ & $-1.7114(0.5453)$ & 0.9371 & $>0.0020$ & 10.01 & 33.25 \\
\hline Larva & $0.0165(0.0712)$ & $39.8302(0.9876)$ & $1.6961(0.3243)$ & $-1.2155(0.1213)$ & 0.9530 & $>0.0010$ & 11.83 & 33.59 \\
\hline Prepupa & $0.0765(0.0129)$ & $39.4740(0.7654)$ & $0.0584(0.0456)$ & $-3.3401(0.2312)$ & 0.9230 & $>0.0031$ & 7.09 & 39.16 \\
\hline Pupa & $0.0095(0.0009)$ & $43.3018(0.8975)$ & $3.1863(1.7887)$ & $-1.1470(0.1289)$ & 0.9600 & $>0.0007$ & 10.02 & 31.81 \\
\hline Immature & $0.0064(0.0008)$ & $43.5186(0.5656)$ & $2.7638(0.9987)$ & $-1.0956(0.6759)$ & 0.9710 & $>0.0003$ & 11.03 & 32.17 \\
\hline
\end{tabular}

\footnotetext{
${ }^{\text {a }}$ Development rate at $25^{\circ} \mathrm{C}\left(298.15^{\circ} \mathrm{K}\right)$ assuming no enzyme inactivation

${ }^{\mathrm{b}}$ Enthalpy of activation of the reaction that is catalyzed by a rate-controlling enzyme

${ }^{\mathrm{c}}$ Kelvin temperature at which the rate-controlling enzyme is half active and half high-temperature inactive

${ }^{\mathrm{d}}$ Change in the enthalpy associated with high-temperature inactivation of the enzyme
} 
The results (Table 1) suggest that B. vulgaris is more tolerant than the boll weevil to high temperatures. Therefore, it is expected that B. vulgaris will have a higher survivorship than the boll weevil during summer in Brazil. The boll weevils that fed on cotton squares began to experience development stress at $34^{\circ} \mathrm{C}$ (Bacheler et al. 1975; Sharpe and Hu 1980). In fact, development rates of the boll weevil (Table 2) are similar to those of Catolaccus grandis (Burks), a parasitoid of boll weevil, at the same temperatures (Bacheler et al. 1975), showing that the life cycles of this parasitoid and its host are remarkably synchronic. This suggests that both species have physiological adaptations to similar ranges of temperatures (MoralesRamos and Cate 1993). However, when the boll weevil feeds on cotton bolls, its development times increase significantly (Sharpe and $\mathrm{Hu}$ 1980). The boll weevil is, therefore, more available to parasitism when it is developing on cotton bolls than on cotton squares. Fortunately, B. vulgaris is better adapted to parasitize boll weevil larvae in cotton bolls.

Bracon mellitor Say, another parasitoid of boll weevil, starts experiencing developmental stress at temperatures close to $38^{\circ} \mathrm{C}$ (Barfield et al. 1977). Therefore, this parasitoid is as tolerant to high temperature as B. vulgaris.

Fit of the models and parameter estimation The high values of $R^{2}$ for the models of Sharpe and DeMichele (1977) (Table 3), and Lactin et al. (1995) (Table 4), showed that they are suitable to estimate the development rate of $B$. vulgaris as a function of temperature.

Temperature inhibition was significant only at the high extreme. Low-temperature inhibition was not significant at the lowest temperature tested $\left(18^{\circ} \mathrm{C}\right)$;
Fig. 1 Relationship between development rate and temperature for development stages of Bracon vulgaris fed on Anthonomus grandis larvae at temperatures from $18^{\circ} \mathrm{C}$ to $35^{\circ} \mathrm{C}, 70 \pm 10 \%$ r.h. and photoperiod of $14 \mathrm{~L} /$ 10D. Dashed lines, Sharpe and DeMichele model; dots, observed values

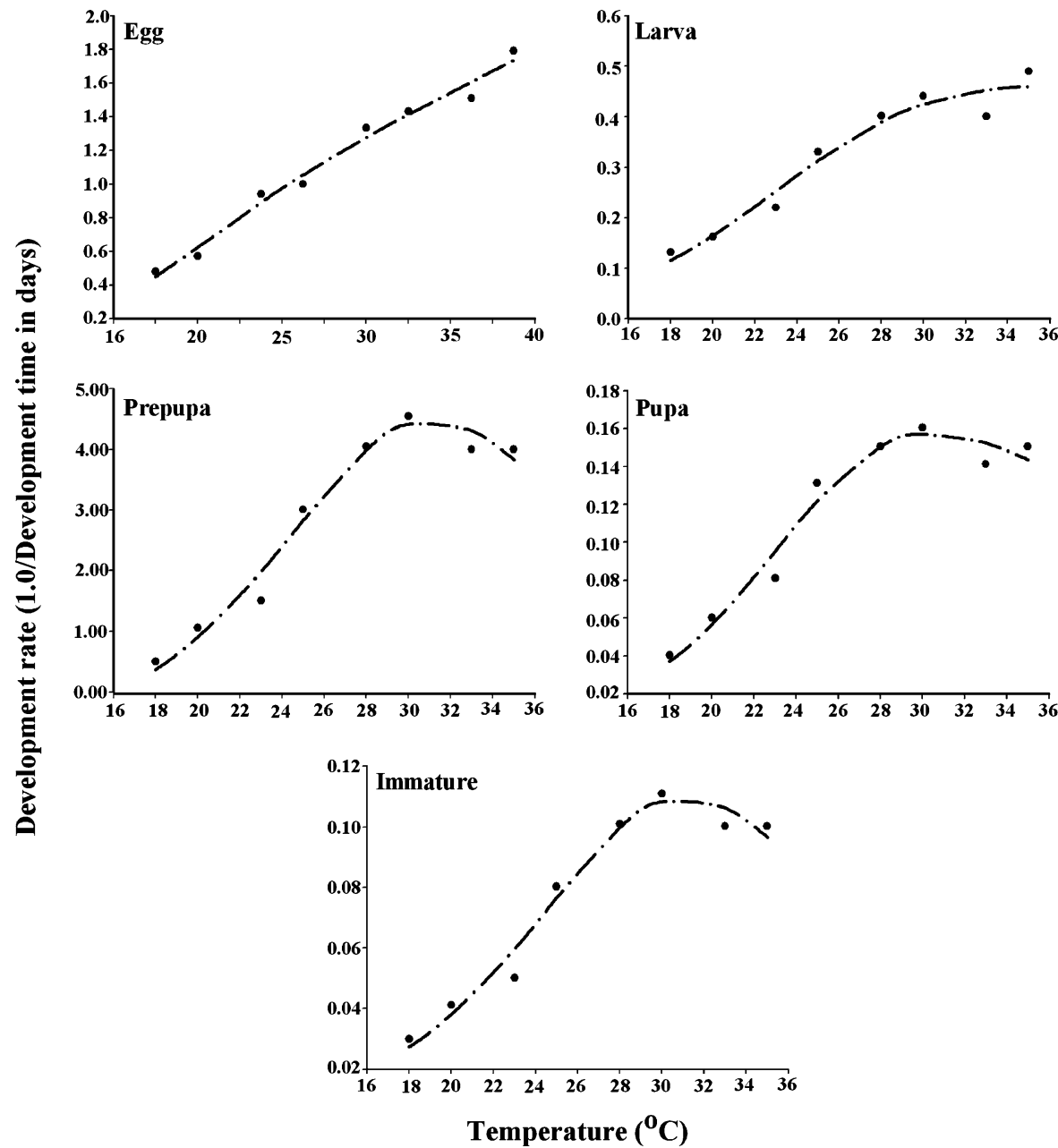


therefore, the four-parameter version (without lowtemperature inhibition) of the Sharpe and DeMichele (1977) model was used, setting $T_{\mathrm{L}}$ and $H_{\mathrm{L}}$ constant at 100 and $10^{8}$, respectively. The test for low-temperature inhibition is an integral part of the Wagner et al. (1984) SAS program and is based on the degree of deviation from linearity. The linear correlation between development rates and temperature of $30^{\circ} \mathrm{C}$ and lower was highly significant $\left(r^{2}=0.9671 ; F_{1,4}=117.63 ; P=\right.$ $0.0004)$, showing no deviation from linearity at the lower temperatures.

The prepupa stage showed the highest tolerance to high temperature, which is represented by the high value of the parameter $H_{\mathrm{H}}$ of the Sharpe and DeMichele (1977) model (Table 3). In the model of Lactin et al. (1995), the high-temperature tolerance of prepupae is shown by the smaller value of $\Delta_{\mathrm{T}}$ (Table 4).
The value of $T_{\mathrm{H}}$ for $B$. vulgaris was $308.9^{\circ} \mathrm{K}$ (Table 3), suggesting this parasitoid will experience thermal stress at $37.75^{\circ} \mathrm{C}$. On the other hand, the value of $T_{\mathrm{H}}$ was $307.6^{\circ} \mathrm{K}$ and $311.7^{\circ} \mathrm{K}$ for the boll weevil and $B$. mellitor, respectively; therefore, these species are expected to experience thermal stress at $34.45^{\circ} \mathrm{C}$ and $38.56^{\circ} \mathrm{C}$, respectively. B. vulgaris appears to have a better tolerance to high temperatures than the boll weevil. It should be pointed out that the characteristics of the Sharpe and DeMichele model tend to predict a thermal maximum that exceeds the maximum observed development rate.

The parameter $T_{\mathrm{L}}$ represents the temperature $\left({ }^{\circ} \mathrm{C}\right)$ at which life can no longer be sustained. The value of this parameter is expressed in degrees Celsius. The value of $T_{\mathrm{L}}$ from the Lactin et al. (1995) model was similar at all development stages of the parasitoid.
Fig. 2 Relationship between development rate and temperature for development stages of Bracon vulgaris fed on Anthonomus grandis larvae at temperatures from $18^{\circ} \mathrm{C}$ to $35^{\circ} \mathrm{C}, 70 \pm 10 \%$ r.h. and photoperiod of 14L/10D. Dashed lines, Lactin et al. model; dots, observed values

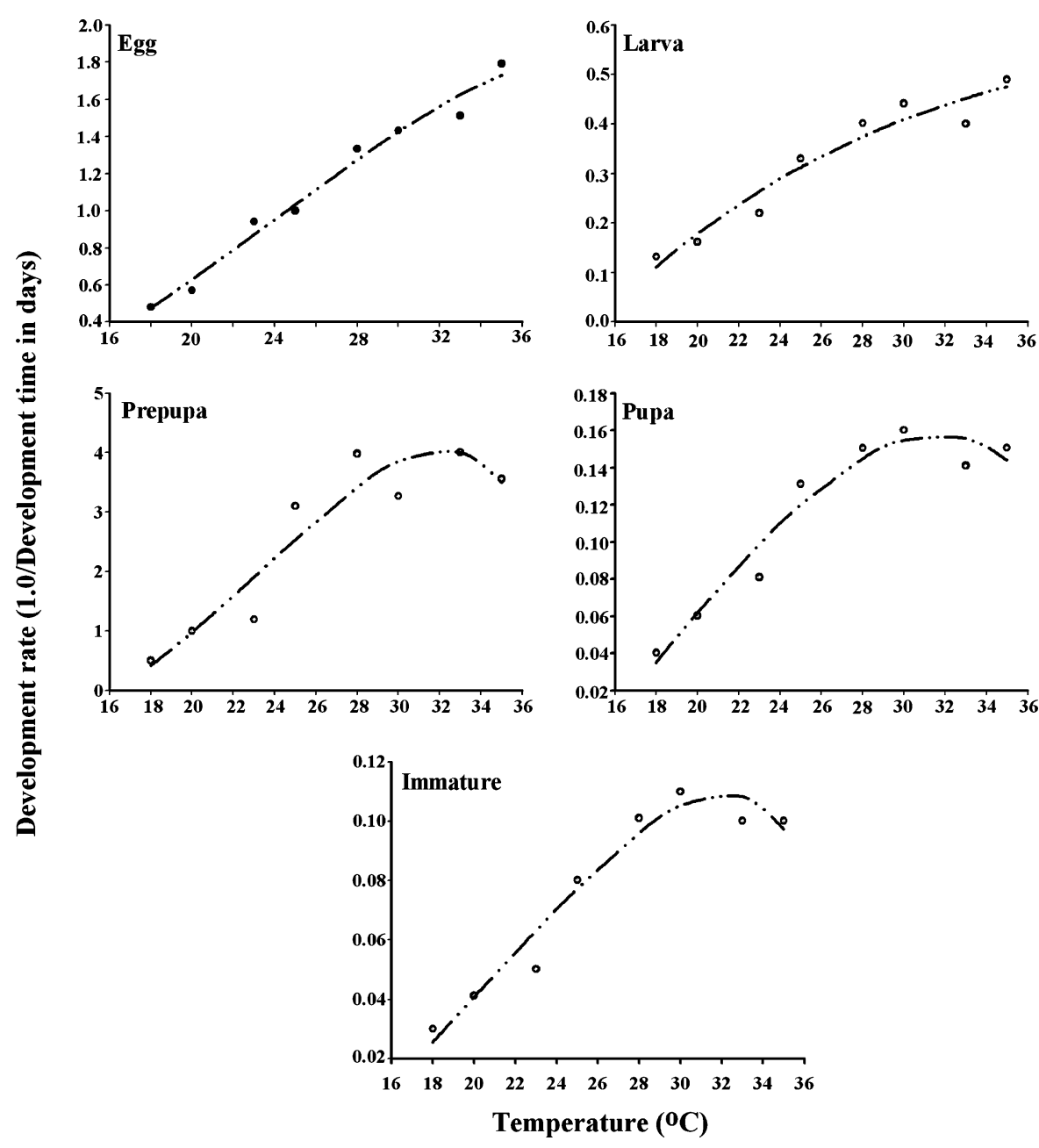


The estimated value of $T_{\mathrm{L}}$ for the immature stage of B. vulgaris was $43.52^{\circ} \mathrm{C}$ (Table 4). The model of Lactin et al. (1995) showed that B. vulgaris is tolerant to high temperatures. The values of $\lambda$ were below zero, indicating that $\lambda$ can estimate the threshold for all development stages of $B$. vulgaris. Values estimated by the $x$-intercept method of Wanderley et al. (2007) and by applying the Lactin et al. (1995) model were similar for each development stage of B. vulgaris (Table 4). As such, the curvilinear relationship of Lactin et al. (1995) and the regression method may be equivalent descriptive tools for a range of temperatures below the upper thresholds. The values of upper thresholds estimated by the model of Lactin et al. (1995) are presented in Table 3. Therefore, the relationship between development rate and temperature for B. vulgaris was appropriately described by the models of Sharpe and DeMichele (1977) (Fig. 1) and Lactin et al. (1995) (Fig. 2).

The estimated values of $T_{\mathrm{L}}$ for the boll weevil, $B$. mellitor and $B$. vulgaris were $39.01{ }^{\circ} \mathrm{C}, 43.51^{\circ} \mathrm{C}$, and $43.52^{\circ} \mathrm{C}$, respectively. According to the model of Lactin et al. (1995), the two parasitoid species have a greater tolerance to high temperatures than the boll weevil. According to the Sharpe and DeMichele (1977) model $\left(T_{\mathrm{H}}\right)$ and the Lactin et al. (1995) model $\left(T_{\mathrm{L}}\right)$, B. vulgaris experiences thermal stress at $37.5^{\circ} \mathrm{C}$ and $43.52^{\circ} \mathrm{C}$, respectively. According to our results, $38^{\circ} \mathrm{C}$ is a harmful temperature for B. vulgaris, where no development occurred. Therefore, it seems that the Sharpe and DeMichele (1977) model better estimates $T_{\max }$ than does the Lactin et al. (1995) model.

The biophysical model of Sharpe and DeMichele (1977) describes a nonlinear response between development rates at low and high temperatures, as well as a linear response at intermediate temperatures. For this reason, Wagner et al. (1984) and Fan et al. (1992) considered that this nonlinear model better describes the effect of constant temperatures on insect development. This model was applied and evaluated by Gould and Elkinton (1990), Orr and Obrycki (1990), Fan et al. (1992), Morales-Ramos and Cate (1993), Harari et al. (1998), and Medeiros et al. (2003) and it was appropriate for determination of the studied development rates.

The two models and the information they provide will be used to determine more accurately the optimal range of conditions for $B$. vulgaris population growth in Brazil. They also will be used to assess other life history characteristics of this parasitoid and similar species now under consideration by the Brazil Department of Agriculture in this multi-state biological control effort.

In summary, both models fit the data (temperaturedependent development rates of $B$. vulgaris) equally well and are equally adequate to simulate development of B. vulgaris under conditions of changing temperatures; however, the model of Sharpe and DeMichele (1977) is to be preferred over that of Lactin et al. (1995) to estimate $T_{\max }$. The values of $T_{\mathrm{H}}$ and $T_{\mathrm{L}}$ from the Sharpe and DeMichele model and the Lactin et al. model, respectively, for B. vulgaris were higher than that obtained for the boll weevil, indicating a better tolerance of $B$. vulgaris to high temperatures.

Acknowledgments The authors thank the Brazilian agencies "Conselho Nacional de Desenvolvimento Científico e Tecnológico (CNPq)" and the "Fundação de Amparo à Pesquisa do Estado de Minas Gerais (FAPEMIG)" for funding. We also express our appreciation to two anonymous experts for their reviews of our manuscript.

\section{References}

Bacheler, J. S., Jones, J. W., Bradley, J. R., \& Bowen, H. D. (1975). The effect of temperature on development and mortality of boll weevil immature stages. Environmental Entomology, 4, 808-810.

Barfield, C. S., Sharpe, P. J. H., \& Bottrell, D. G. (1977). A temperature-driven developmental model for the parasite Bracon mellitor (Hymenoptera: Braconidae). Canadian Entomologist, 109, 1503-1514.

Curry, G. L., \& Feldman, R. M. (1987). Mathematical foundations of population dynamics. TEES Monogram Series, College Station, TX, USA.

Fan, Y., Groden, E., \& Drummond, F. A. (1992). Temperaturedependent development of the Mexican bean beetle (Coleoptera: Coccinellidae) under constant and variable temperatures. Journal of Economic Entomology, 85, 1762-1770.

Freund, R. J., \& Littell, R. C. (1986). SAS system for regression. Cary, NC, USA: SAS Institute.

Gould, J. R., \& Elkinton, J. S. (1990). Temperature-dependent growth of Cotesia melanoscela (Hymenoptera: Braconidae), a parasitoid of the gypsy moth (Lepidoptera: Lymantriidae). Environmental Entomology, 19, 859-865.

Harari, A. R., Ben-Yakir, D., Chen, M., \& Rosen, D. (1998). Temperature-dependent developmental models for predicting the phenology of Maladera matrida (Coleoptera: Scarabaeidae). Environmental Entomology, 27, 1220-1228.

Howe, R. W. (1967). Temperature effects on embryonic development in insects. Annual Review of Entomology, $10,15-42$. 
Lactin, D. J., Holliday, N. J., Johnson, D. L., \& Craigen, R. (1995). Improved rate model of temperature-dependent development by arthropod. Environmental Entomology, $24,68-75$.

Logan, J. A., Wollkind, D. J., Hoyt, S. C., \& Tanigoshi, L. K. (1976). An analytic model for description of temperature dependent rate phenomena in arthropods. Environmental Entomology, 5, 1133-1140.

Marco, V., Taberner, A., \& Castanera, P. (1997). Development and survival of immature Aubeonymus mariaefranciscae (Coleoptera: Curculionidae) at constant temperatures. Annals of the Entomological Society of America, 90, 169-176.

Medeiros, R. S., Ramalho, F. S., Serrão, J. E., \& Zanuncio, J. C. (2003) Estimate of Podisus nigrispinus (Dallas) (Heteroptera: Pentatomidae) development time with nonlinear models. Neotropical Entomology, 33, 141-148.

Morales-Ramos, J. A., \& Cate, J. R. (1993). Temperaturedependent rates of Catolaccus grandis (Hymenoptera: Pteromalidae). Environmental Entomology, 22, 226-233.

Orr, C. J., \& Obrycki, J. J. (1990). Thermal and dietary requirement for development of Hippodamia parenthesis (Coleoptera: Coccinellidae). Environmental Entomology, 19, 1523-1527.

Ramalho F. S., Gonzaga J. V., \& Silva, J. R. B. (1993). Métodos para determinação das causas de mortalidade natural do bicudo-do-algodoeiro. Pesquisa Agropecuária Brasileira, $28,877-887$.

SAS Institute. (2004). SAS user's guide: Statistics. Cary, NC, USA.

Schoolfield, R. M., Sharpe, P. J. H., \& Magnuson, C. E. (1981). Non-linear regression of biological temperature-dependent rate models based on absolute reaction-rate theory. Journal of Theoretical Biology, 88, 719-731.

Sharpe, P. J. H., \& DeMichele, D. W. (1977). Reactions kinetics of poikilotherm development. Journal of Theoretical Biology, 64, 649-670.

Sharpe, P. J. H., \& Hu, L. C. (1980). Reactions kinetics of nutrition-dependent poikilotherm development. Journal of Theoretical Biology, 82, 317-333.

Uvarov, B. P. (1931). Insects and climate. Transactions of the Epidemiological Society of London, 79, 1-247.

Wagner, T. L., WuH., Sharpe, P. J. H., Schoolfield, R. M. E., \& Coulson, R. N. (1984). Modeling insect development rates: A literature review and an application of a biophysical model. Annals of the Entomological Society of America, 77, 208-225.

Wanderley, P. A., Ramalho, F. S., Zanuncio, J. C., \& Leite, G. L. D. (2007). Thermal requirements and development of Bracon vulgaris, a parasitoid of the cotton boll weevil. Phytoparasitica, 35, 336-345. 